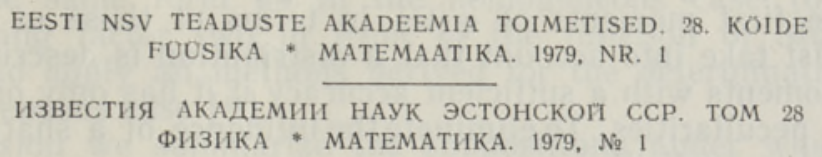

J. KIKAS

удК $535.372: 539.219 .1$

\title{
DETERMINATION OF HOMOGENEOUS IMPURITY SPECTRA IN STRONGLY INHOMOGENEOUS SOLIDS
}

J. KIKAS. HOMOGEENSE LISANDISPEKTRI MAARAMINE TUGEVALT MITTEHOMOGEENSETES TAHKETES MAATRIKSITES

Я. КИКАС. ОПРЕДЕЛЕНИЕ ОДНОРОДНОГО ПРИМЕСНОГО СПЕКТРА В СИЛЬНО НЕОДНОРОДНЫХ ТВЕРДЫХ МАТРИЦАХ

(Presented by K. K. Rebane)

It is evident that the low-temperature impurity molecule spectra in solids are inhomogeneously broadened $\left(\left[{ }^{1}\right]\right.$, p. 162). Particularly large inhomogeneous broadening is observed in the spectra of organic impurities in glassy or polycrystalline matrices $\left[{ }^{2-4}\right]$. Because of the presence of broad phonon wings in homogeneous spectrum $\left[{ }^{1,5}\right]$, it is not of a trivial matter to restore the homogeneous spectrum even by a monochromatic excitation $\left.{ }^{6}\right]$. For a model considering only the different shifts of homogeneous spectra for different impurity molecules without any shape distortion, a general result was given in $\left.{ }^{7}\right]$. The aim of this paper is to show that in the case of large inhomogeneous broadening some simplification occurs and equations can be derived relating the moments of the homogeneous spectrum to those of the measured fluorescence spectrum under monochromatic excitation. The latter makes possible an approximate reconstruction of the homogeneous spectrum.

As generalizations are obvious, the case of purely electronic line and its phonon wing is considered only.

Let us suppose the function of inhomogeneous distribution of molecules by the $0-0$ transition frequency $\omega$ to be constant within the width of the phonon wing (wide distribution). Then the formula describing the monochromatically excited fluorescence spectrum $I\left(v_{e}, v_{f}\right)\left[{ }^{6}\right]$ is simplified:

$$
I\left(v_{e}, v_{f}\right)=A \int_{-\infty}^{\infty} x\left(v_{e}-\omega\right) \varphi\left(v_{f}-\omega\right) d \omega .
$$

Here $v_{e}$ is the excitation frequency, $v_{f}$ - the frequency of registration, $x$ and $\varphi$ - the homogeneous spectra of absorption and fluorescence (consisting of no-phonon line and its phonon wing), respectively, $A$ is a constant (further taken as unit). Supposing $x$ to be the mirror image of $\varphi\left(\left[{ }^{1}\right]\right.$, p. 86), (1) can be rewritten as

$$
I\left(v_{e}, v_{f}\right) \equiv J(\Omega)=\int_{-\infty}^{\infty} \varphi(\Omega-\omega) \varphi(\omega) d \omega \equiv \varphi * \varphi, \Omega=v_{f}-v_{e},
$$


with $*$ denoting the convolution. In principle, integral equation (1a) can be solved with respect to $\varphi(\Omega)$, but there rise some complications related to the necessary regularization procedure $\left[{ }^{8}\right]$. It is more convenient to express some first moments of $\varphi(\Omega)$ in terms of those of $J(\Omega)$. However, one must take into account that a distribution is described by some of its first moments with a sufficient accuracy if it has only one maximum and no sharp peculiarities. To eliminate the influence of a sharp no-phonon line, we express explicitly

$$
\varphi(\Omega)=\alpha \delta(\Omega)+(1-\alpha) \varphi_{p}(\Omega) .
$$

Here the no-phonon line is replaced by a $\delta$-function, index $p$ denotes the phonon wing, $\alpha$ is the Debye-Waller factor ( $\varphi_{p}$ is normalized to one). (2) is a good approximation if one is interested in the shape of only phonon wing. Substitution of (2) into (1a) gives

$$
J=\alpha^{2} \delta+2 \alpha(1-\alpha) \varphi_{p}+(1-\alpha)^{2} \varphi_{p} * \varphi_{p} .
$$

In what follows we exclude the $\delta$-term from (3) and consider only the remaining ones denoted as $J_{p}$. Experimentally the separation of this term from the remaining spectrum is a performable procedure for sharp nophonon lines and moderate Stokes' losses. This also allows to determine the value of $\alpha$ from the experiment, as $\alpha^{2}$ is the ratio of integral intensities of the separated sharp line and the whole spectrum $J(\Omega)$. Using (3) one can now derive formulas for moments of $\varphi_{p}(\Omega)$. The simplest way to obtain them is to perform the Fourier' transformation of $J_{p}(\Omega)$ and to calculate the derivatives needed $\left[{ }^{9}\right]$. This gives

$$
\begin{aligned}
M_{1}\left(\varphi_{p}\right) & =a M_{1}\left(J_{p}\right), \\
M_{2}\left(\varphi_{p}\right) & =a M_{2}\left(J_{p}\right)-a^{2} b M_{1}^{2}\left(J_{p}\right), \\
M_{3}\left(\varphi_{p}\right) & =a M_{3}\left(J_{p}\right)-3 a^{2} b M_{1}\left(J_{p}\right) M_{2}\left(J_{p}\right)+3 a^{3} b^{2} M_{1}^{3}\left(J_{p}\right), \\
M_{4}\left(\varphi_{p}\right) & =a M_{4}\left(J_{p}\right)-4 a^{2} b M_{3}\left(J_{p}\right) M_{1}\left(J_{p}\right)-3 a^{2} b M_{2}^{2}\left(J_{p}\right)- \\
& -15 a^{4} b^{3} M_{1}^{4}\left(J_{p}\right)+18 a^{3} b^{2} M_{2}\left(J_{p}\right) M_{1}^{2}\left(J_{p}\right) .
\end{aligned}
$$

Here $M_{i}$ denotes the normalized $i$-th moment, $a=(1+\alpha) / 2, b=1-\alpha$. If now the phonon wing has no sharp peculiarities, its shape can be reconstructed in a good approximation ([ $\left.{ }^{1}\right]$, p. 218). If higher moments of $\varphi_{p}$ are needed, they can be calculated by a recurrent formula

$$
M_{k}\left(\varphi_{p}\right)=a M_{k}\left(J_{p}\right)-b F_{k}\left[M_{1}\left(\varphi_{p}\right), \ldots, M_{k-1}\left(\varphi_{p}\right)\right] .
$$

Here $F_{k}$ is got by replacing $M_{i}(1 \leqslant i \leqslant k-1)$ for $f^{(i)}$ into

$$
\frac{1}{2}\left[f^{2}\right]^{(k)}-f \cdot f^{(k)},
$$

where $f^{(i)}$ denotes the $i$-th derivative of the function $f$.

It should be mentioned that if one is interested in the shape of the homogeneous spectrum $\varphi(\Omega)$ in order to determine the function of Stokes' losses $S(\Omega)$, the problem is still simpler. Fourier' transforms of $\varphi$ and $S$ are related by

$$
\tilde{\varphi}(t)=\mathrm{e}^{\tilde{\mathrm{S}}(t)-\tilde{\mathrm{S}}(0)}\left[{ }^{10}\right] .
$$

Then from (1a) an expression for Fourier' transform of the spectrum measured follows: 


$$
\tilde{J}(t)=\tilde{\varphi}^{2}(t)=\mathrm{e}^{2 \tilde{S}(t)-2 \tilde{S}(0)} .
$$

(7) is of the same form as in the homogeneous case (6), the only difference being factor two in front of the function of Stokes' losses. This allows to apply all methods derived for the determination of $S(\Omega)$ in the homogeneous case [ $\left.{ }^{11}\right]$.

In conclusion we summarize the suppositions under which (4), (5) hold: (i) the sample is optically thin and of low impurity concentration (ensuring a uniform excitation of all impurity molecules and excluding the effects of reabsorption and nonradiative energy transfer), (ii) the homogeneous emission spectrum is the mirror image of the homogeneous absorption spectrum, (iii) the inhomogeneity of solid matrix acts only in different shifts of homogeneous spectra without any shape distortion, (iv) the inhomogeneous broadening is large (the inhomogeneous distribution function is constant within the width of the homogeneous phonon wing). Condition (i) can be experimentally easily satisfied, (ii), (iii) are good approximations for the systems with moderate or weak impurity matrix interaction $\left[{ }^{1}\right]$, (iv) can be proved experimentally $\left[{ }^{12}\right]$. However, if some deviation from (iv) still occurs, (4), (5) may be used as useful approximations.

The author is indebted to K. Rebane, P. Saari and T. Tamm for stimulating discussions.

\section{REFERENCES}

1. Р ебане К. К., Элементарная теория колебательной структуры спектров примесных центров кристаллов, М., «Наука», 1968.

2. Personov, R. I., A l'shits, E. I., B ykovskaya, L. A., Opt. Communs., 6, № 2, 169-173 (1972).

3. А в ар ма а Р., Ребане К., Изв. АН ЭССР, Физ. Матем., 22, № 1, $108-110$ (1973).

4. Rebane, K. K., In: Abstr. of VIII Nat. Conf. on Spectroscopy, Slanchev Bryag, Bulgaria, 1976, p. 12.

5. Ребане К., Саари П., Т амм Т., Изв. АН ЭССР, Физ. Матем., 19, № 2, $251-254(1970)$.

6. А в а р м а а Р., Изв. АН ЭССР, Физ. Матем., 23, № 3, 238-247 (1974).

7. К и к а с Я., Изв. АН ЭССР, Физ. Матем., 25, № 4, 374-379 (1976).

8. Т ур ч и В. Ф., Т ур овцев а Л. С., Ӧптика и спектроскопия, 36, вып. 2, 280287 (1974).

9. Прохоров Ю. В., Розанов Ю. А., Теория вероятностей, М., «Наука», 1967.

10. П е р ли н Ю. Е., Успехи физ. наук, 80, № 4, 553-595 (1963).

11. Л о о и т с В. А., Р е бан е К. К., Тр. ИФА АН ЭССР, № 32, 3-15 (1967)

12. Т а м м Т. Б., Кик а с Я: В., Си к К А. Э., Ж. прикладной спектроскопии, 24, № 2, $315-321(1976)$.

Academy of Sciences of the Estonian SSR, Institute of Physics

Received May 22, 1978 